\title{
Excess paste method to formulate a self-compacting concrete
}

\author{
Mebrouki A*, Bendani K, Bouhamou N and Belas N
}

LCTPE Laboratory, UMAB-Mostaganem University, BP 227, 27000 Mostaganem, Algeria.

Corresponding Author: mebroukiaek@yahoo.fr, Tel \& Fax: +213 45203933.

\begin{abstract}
On the basis of the principle that a concrete is composed of a liquid phase (paste) and a solid phase (aggregates with fixed gravel/sand ratio), the concrete self-compacting properties come necessarily from those of the paste. The present work is the continuity of a first phase of the testing already conducted, which resulted in obtaining an optimal selfcompacting cement paste composition. This paste will be used to prepare a self-compacting concrete (SCC), while passing from the scale of the cement paste to that of the concrete, by injecting wet aggregate to the self-compacting paste. The excess paste theory was used to determine the thickness of the paste coating each aggregate with a given diameter of constituting granular skeleton, then generalized for the determination of the quantity of total paste allowing the flow of the concrete by decreasing frictions between the grains of its granular skeleton. This approach was also experimentally validated. The influence of the granular distribution was minimized by the use of the approach based on the determination of the average diameter of the aggregates. This required the determination of a homothetic factor " $k$ " similar for all concretes with different aggregate grading. Formulation of a selfcompacting concrete passes initially by the determination of a sufficient quantity of paste allowing its flow without frictions between its aggregates and to balance the mixture by the quantity of water retained by the aggregates. The self-compacting concrete characteristics would come from those of the cement paste which composes it.
\end{abstract}

Key words: Self-compacting concrete, Excess paste method, Homothetic, Compactness, Formulation.

\section{Introduction}

Concrete is a biphasic material, consisting of a fluid phase (paste) and a solid phase (aggregates with fixed gravel/sand ratio (Nanthagopalan, 2010). The self-compacting concrete properties result inevitably from those of the paste (Pedersen, 2003). In this context, the studies of formulations were based on paste and its constituents. A first phase already conducted, concerned the determination of the optimal composition of the self-compacting cement paste (Mebrouki, 2010). This paste will serve to elaborate a self-compacting concrete by injecting into it wet aggregates. Table 1 presents constituents proportions necessary to elaborate a volume of paste $\left(V_{P}=0.225 \mathrm{~m}^{3}\right)$ of the optimal self-compacting paste.

Table 1. Composition of the optimal paste.

\begin{tabular}{|c|c|c|c|c|}
\hline Component & Volume $\left(\mathrm{m}^{3}\right)$ & Density $\left(\mathrm{Kg} / \mathrm{m}^{3}\right)$ & Mass (Kg) & Rate (\%) \\
\hline \hline Cement (C) & 0.111 & 3150 & 349.65 & $86.6 \%$ \\
\hline Filler (F) & 0.021 & 2800 & 58.80 & $14.4 \%$ \\
\hline Superplasticizer (Sp) & 0.005 & 1085 & 05.43 & $1.3 \%$ \\
\hline Water (W) & 0.088 & 1000 & 88.00 & $\mathrm{~W} /(\mathrm{C}+\mathrm{F})=0.22$ \\
\hline
\end{tabular}

Using this paste with a granular skeleton defined only by a weight ratio gravel/sand (G/S), it would be possible to make concretes satisfying the self-compacting criteria admitted in the fresh state.

For a chosen granular skeleton having defined G/S weight ratio, a sufficient optimal selfcompacting paste is prepared, to which will be added the granular mixture; a part of this paste is going to cover the aggregates and the rest fits between these grains and fills the space, thus causing separation of the skeleton, which would induce a difficulty of flow of the concrete thus formed. 
In addition, sand and gravels have a capacity for absorption of considerable water; this water if absorbed will cause a deficiency in the paste composition, it is necessary thus to correct it by water addition to compensate this deficit. It is difficult to compensate the adsorbed water but even more difficult to be able to calculate theoretically this quantity, since this one would have already caused an increase in the capillary pores.

\section{Principle of the formulation method}

The method used gave conclusive results with materials employed in Materials and Constructions Durability Laboratory (L.M.D.C - Applied Sciences National Institute - UPS, Toulouse, France), it will be then applied to Algerian local materials to formulate a selfcompacting concrete.

Figure 1 schematizes the formulation principle to elaborate a self-compacting concrete.

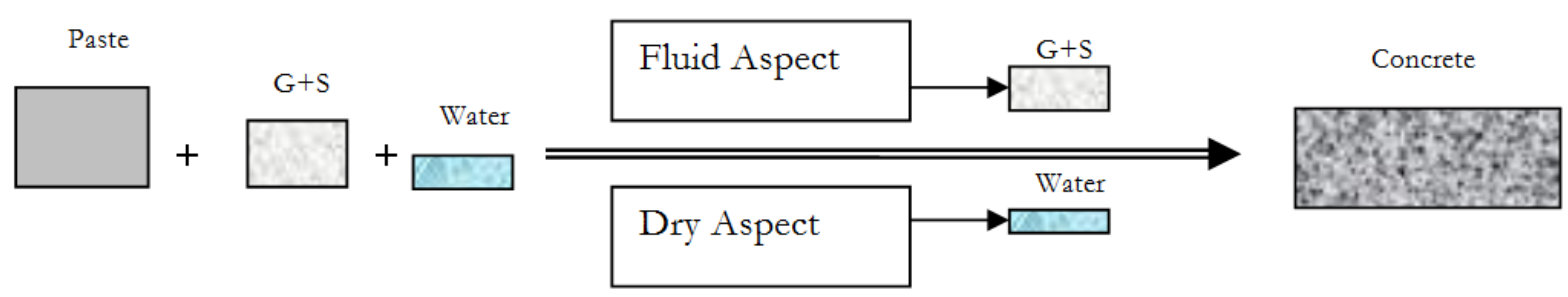

Fig 1. SCC formulation principle.

In the following, it is presented the conventional hypothesis to formulate $1 \mathrm{~m}^{3}$ of SCC. For that purpose, it is necessary to determine the corresponding volume of cement paste, the volume of aggregates to be injected (with fixed G/S ratio) and that of water to be added. The unit volume of the concrete finally obtained contains a volume of the pores estimated at $2.5 \%$ of total volume.

The following first equation can be written:

$V=V_{P}+V_{A}+V_{V}$

$V$ : Unit volume of concrete $\left(1 \mathrm{~m}^{3}\right)$.

$V_{P}$ : Optimal self-compacting paste absolute volume.

$V_{A}$ : Added volume accumulates of aggregates and water absolute volumes.

$V_{V:}$ Volume of occluded voids in concrete $(2.5 \%)$.

To be able to work out a SCC on the basis of a self-compacting paste of volume $\left(V_{P}\right)$, one gradually adds alternate volumes of aggregates and water during the kneading, while observing the aspect of the concrete which must resemble that of a SCC. The procedure will be stopped when the sum of added volumes would have reached the volume $\left(V_{A}\right)$.

\section{Paste- granular skeleton association}

Aggregates with G/S ratio varying from 0.8 and 1.2 were chosen to elaborate the concretes. In addition to the tests of determination of experimental compact nesses on the basis of stacking compressible model, the determination of the water quantity retained by the aggregates is also necessary since, if the aggregates are not humidified beforehand, they would draw water of the paste with which they will be mixed.

\subsection{Granular skeleton characterization results}

Table 2 gives the various granular grading going from 0.08 to $16 \mathrm{~mm}$. The representative (DRi) and arithmetic average diameters (Dami) were calculated theoretically by suitable formulas (Bui, 2002; EL-Barrak, 2009). These values will be used as data for the continuation of work. 
These values represent various sections of different granular classes chosen to calculate experimental compactness.

Table 2. Representative and arithmetic diameters of the granular classes.

\begin{tabular}{|c|c|c|c|}
\hline $\mathrm{N}^{\circ}$ Class & Granular class & DRi (mm) & Dami(mm) \\
\hline \hline 1 & $12,5-16$ & 14,106 & 14,25 \\
\hline 2 & $6,3-12,5$ & 8,75 & 9,4 \\
\hline 3 & $3,15-6,3$ & 4,368 & 4,725 \\
\hline 4 & $1,25-3,15$ & 1,917 & 2,2 \\
\hline 5 & $0,315-1,25$ & 0,583 & 0,7825 \\
\hline 6 & $0,08-0,315$ & 0,148 & 0,1975 \\
\hline
\end{tabular}

Found values are in the interval [150 - $300 \mu \mathrm{m}$ ] which comply with that recommended by (Bui, 2002). Tests of compactness were made to estimate the experimental and the maximal compactness, according to the DRi and the Dami given in Table 3, according to the granular pile model (Nanthagopalan, 2010).

Table 3. Experimental and maximal calculated compactness values.

\begin{tabular}{|c|c|c|c|}
\hline \multirow{2}{*}{ G/S } & \multirow{2}{*}{$\begin{array}{l}\text { Experimental } \\
\text { compactness }(\gamma)\end{array}$} & \multicolumn{2}{|c|}{ Maximal compactness } \\
\cline { 3 - 4 } & with DRi & with Dami \\
\hline \hline 0.8 & 0.729 & 0.782 & 0.801 \\
\hline 1 & 0.731 & 0.801 & 0.807 \\
\hline
\end{tabular}

Water filtration passes by three stages, an initial and fast phase corresponding to the filtration of the water in excess in the heap of aggregates, the second stage in which the water results from capillary meniscus destruction by pumping strengths, then the third and slower phase of water recovery contained in aggregates pores, it is the water retained by the aggregates which quantification is researched. For $G / S=0.8$ and $G / S=1$, this quantity corresponds to points (P1) and (P2) respectively (Figure 2).

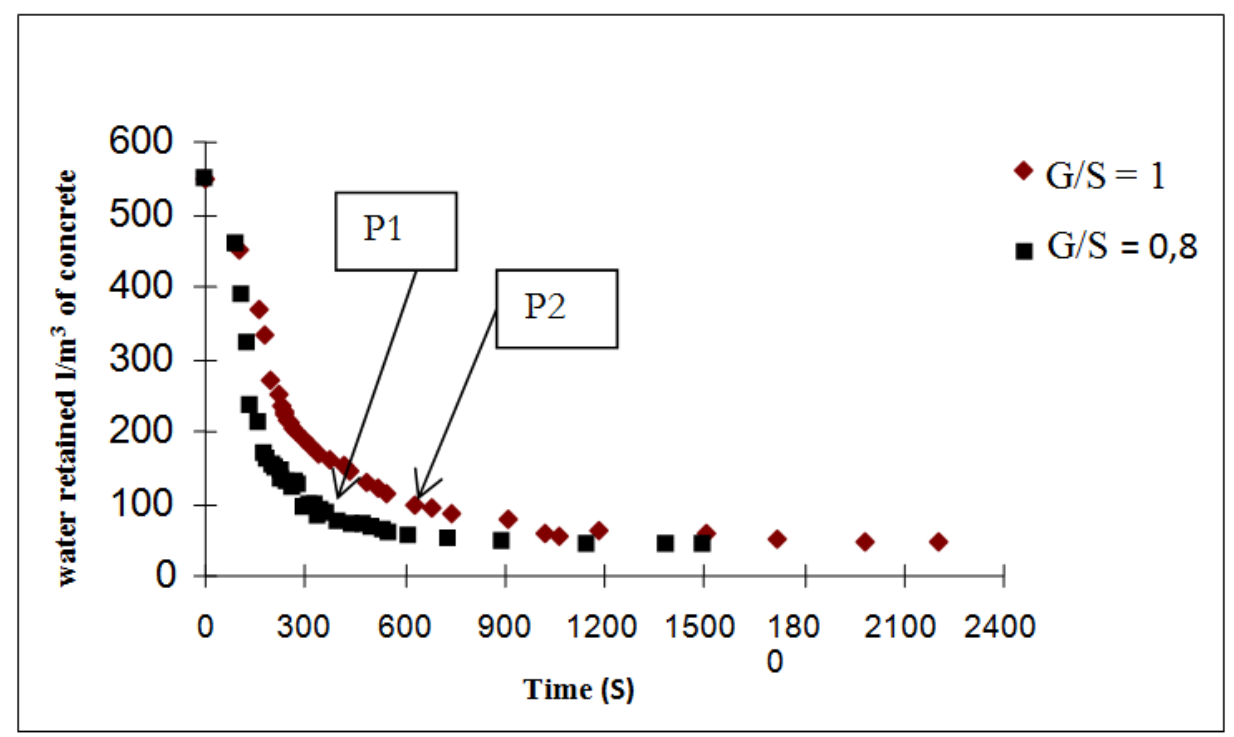

Fig 2. Filtration curves for $G / S=0.8$ and $G / S=1$.

Obtained results are gathered in Table 4. The total water represents the sum of paste water and added water.

Table 4. Retained water and added water to concretes.

\begin{tabular}{|c|c|c|c|}
\hline \multicolumn{1}{|l|}{$\mathrm{G} / \mathrm{S}$} & Retained water $\left(\mathrm{l} / \mathrm{m}^{3}\right.$ of concrete $)$ & Total water & complement \\
\hline \hline 0.8 & 147 & 196 & 49 \\
\hline 1 & 165 & 188 & 23 \\
\hline
\end{tabular}




\subsection{Homothety factor determination}

Homothety factor determination is based on paste excess theory. The representative plan (Figure 3) shows a concrete (biphasic mixture) with aggregates immersed in cement paste. The compaction highlights a part of volume $\left(\mathrm{V}_{\mathrm{pe}}\right)$ representing excess paste coating of aggregates, a second part constituted by squeezed aggregates (volume $\mathrm{V}_{\mathrm{G}}$ ) and a compact paste (volume $\mathrm{V}_{\mathrm{pc}}$ ) serving to fill voids.
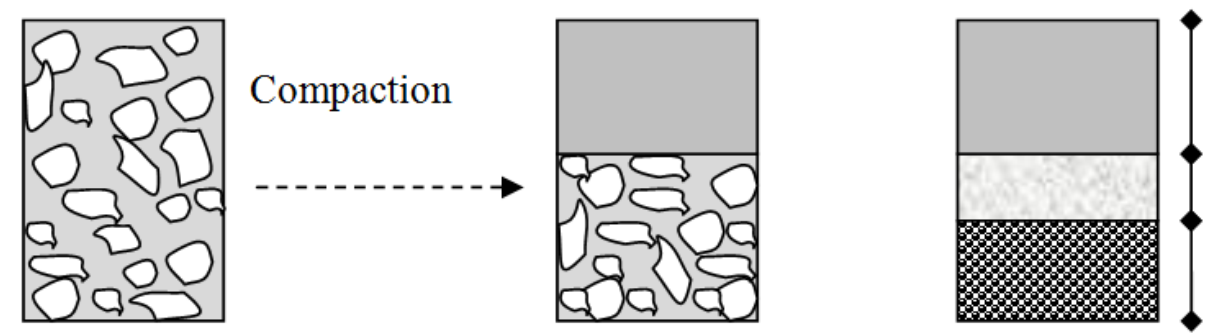

Excess paste $\left(\mathrm{V}_{\mathrm{pe}}\right)$

Compact paste $\left(\mathrm{V}_{\mathrm{pc}}\right)$

Aggregates $\left(V_{G}\right)$

Fig 3. Explanatory plan of the excess paste theory.

Homothety factor for every ratio $(\mathrm{G} / \mathrm{S})$ can be determined by the following relation:

$k=\sqrt[3]{1+\frac{6 \cdot\left(V_{p e}\right)}{\pi \cdot \sum N_{i} \cdot D_{i}^{3}}}=\sqrt[3]{1+\frac{\left(V_{p e}\right)}{V_{G>80}}}$

$\left(\mathrm{N}_{\mathrm{i}}\right)$ is aggregates number with diameter $\left(\mathrm{D}_{\mathrm{i}}\right)$ of the class (i), $\mathrm{V}_{\mathrm{G}}>80$ is aggregates volume with diameters greater than $80 \mu \mathrm{m}$ (without fillers). Found values are given in Table 5 .

Table 5. Homothety factor values.

\begin{tabular}{|c|c|}
\hline G/S & Homothety facteur $\mathrm{k}$ \\
\hline 0.8 & 1.141 \\
\hline 1 & 1.131 \\
\hline
\end{tabular}

\subsection{Validation on concretes}

In self-compacting paste already formulated, aggregates were injected in alternate way with a certain quantity of water to obtain concretes of which workability depends initially on the visual aspect. Indeed, if the mixture seems firm, a moderate quantity of water is added, if contrary, it presents a fluid aspect, a known aggregates quantity is injected. Table 6 illustrates a concrete preparation example with $\mathrm{G} / \mathrm{S}=1$.

Table 6. Procedure of alternated additions.

\begin{tabular}{|c|c|c|c|c|}
\hline Stage & $\begin{array}{l}\text { Volumes of added } \\
\text { aggregates (accumulated) }\end{array}$ & $\begin{array}{l}\text { Volume of added } \\
\text { Water (accumulated) }\end{array}$ & $\begin{array}{l}\text { Visuel } \\
\text { aspect }\end{array}$ & $\begin{array}{l}\text { Total volume } \\
\text { added }\end{array}$ \\
\hline \hline 1 & $0.65 \mathrm{VA}$ & 0 & $\begin{array}{l}\text { Pulverulent and } \\
\text { heterogeneous }\end{array}$ & $0.65 \mathrm{VA}$ \\
\hline 2 & $0.65 \mathrm{VA}$ & $0.08 \mathrm{VA}$ & Very firm and sticky & $0.73 \mathrm{VA}$ \\
\hline 3 & $0.65 \mathrm{VA}$ & $0.10 \mathrm{VA}$ & Fluid & $0.75 \mathrm{VA}$ \\
\hline 4 & $0.70 \mathrm{VA}$ & $0.10 \mathrm{VA}$ & Plastic & $0.80 \mathrm{VA}$ \\
\hline 5 & $0.70 \mathrm{VA}$ & $0.12 \mathrm{VA}$ & Fluid & $0.82 \mathrm{VA}$ \\
\hline 6 & $0.76 \mathrm{VA}$ & $0.12 \mathrm{VA}$ & Firm & $0.88 \mathrm{VA}$ \\
\hline 7 & $0.76 \mathrm{VA}$ & $0.15 \mathrm{VA}$ & Fluid & $0.91 \mathrm{VA}$ \\
\hline 8 & $0.79 \mathrm{VA}$ & $0.15 \mathrm{VA}$ & Firm & $0.94 \mathrm{VA}$ \\
\hline 9 & $0.79 \mathrm{VA}$ & $0.17 \mathrm{VA}$ & Pasty & $0.96 \mathrm{VA}$ \\
\hline 8 & $0.81 \mathrm{VA}$ & $0.17 \mathrm{VA}$ & Acceptable & $0.98 \mathrm{VA}$ \\
\hline 9 & $0.81 \mathrm{VA}$ & $0.18 \mathrm{VA}$ & Satisfactory & $0.99 \mathrm{VA}$ \\
\hline 10 & $0.82 \mathrm{VA}$ & $0.18 \mathrm{VA}$ & Satisfactory & VA \\
\hline
\end{tabular}


This alternation ends by workability tests recommended by the French Civil Engineering Association (AFGC, 2008) to verify self-compacting properties, and by measures of compressive strength at age of 28 days. Results are illustrated in Table 7.

Table 7. Results of SCC characterization $(G / S=0.8$ and $G / S=1)$.

\begin{tabular}{|c|c|c|c|c|}
\hline \multicolumn{2}{|l|}{ G/S } & 0.8 & 1 & AFGC Recommandations \\
\hline \hline \multirow{2}{*}{ Abrams cone } & $\mathrm{T}_{50}(\mathrm{~s})$ & 2.1 & 1.8 & Not specified \\
\cline { 2 - 5 } & $\mathrm{Dmoy}(\mathrm{mm})$ & 693 & 712 & $600-750 \mathrm{~mm}$ \\
\hline \multirow{2}{*}{$\mathrm{L}$ Box } & $\mathrm{T}_{40}(\mathrm{~s})$ & 1.8 & 1.2 & Not specified \\
\cline { 2 - 5 } & $\mathrm{H}_{2} / \mathrm{H}_{1}$ & 0.89 & 0.92 & $\geq 0.8$ \\
\hline \multicolumn{2}{|c|}{ Sieve Stability $\% \%$} & 9.65 & 11.02 & $\leq 15 \%$ \\
\hline \multicolumn{2}{|c|}{ Occluded Air \% } & 2.6 & 2.9 & Not specified \\
\hline \multicolumn{2}{|c|}{ Density $\left(\mathrm{Kg} / \mathrm{m}^{3}\right)$} & 2290 & 2310 & Not specified \\
\hline \multicolumn{2}{|c|}{ Compressive strength $\mathrm{Rc}_{28}(\mathrm{MPa})$} & 33.2 & 38.7 & Not specified \\
\hline
\end{tabular}

Results obtained show that the properties of the concrete at fresh state are in accordance with AFGC requirements. Concrete obtained is then a self-compacting concrete, this is due to the narrow relation between the excess paste and the flow (Wong, 2008). To verify suitability of the found formulation, components parameters were estimated and used to make concretes in a traditional way. The characterization results obtained are shown in Table 8.

Table 8. Characterization results of concretes made in a classical way

\begin{tabular}{|c|c|c|c|}
\hline \multicolumn{2}{|l|}{$\mathrm{G} / \mathrm{S}$} & 0.8 & 1 \\
\hline \hline \multirow{2}{*}{ Abrams cone } & $\mathrm{T}_{50}(\mathrm{~s})$ & 1.8 & 1.8 \\
\cline { 2 - 4 } & $\mathrm{Dmoy}(\mathrm{mm})$ & 728 & 712 \\
\hline \multirow{2}{*}{$\mathrm{L}$ Box } & $\mathrm{T}_{40}(\mathrm{~s})$ & 2.1 & 1.2 \\
\cline { 2 - 4 } & $\mathrm{H}_{2} / \mathrm{H}_{1}$ & 0.91 & 0.92 \\
\hline \multicolumn{2}{|c|}{ Sieve Stability $\pi \%$} & 11.96 & 9.54 \\
\hline \multicolumn{2}{|c|}{ Occluded Air \% } & 2.3 & 1.9 \\
\hline \multicolumn{2}{|c|}{ Density $\left(\mathrm{Kg} / \mathrm{m}^{3}\right)$} & 2290 & 2310 \\
\hline \multicolumn{2}{|c|}{ Compressive strength $\mathrm{Rc}_{28}(\mathrm{MPa})$} & 36.4 & 40.2 \\
\hline
\end{tabular}

\subsection{Application example for validation}

For various granular mixtures with variable ratios $G / S$, and with values of the coefficient "k" previously calculated, Figure 4 can be plotted. This illustration allows determining values of this coefficient corresponding to different ratios G/S.

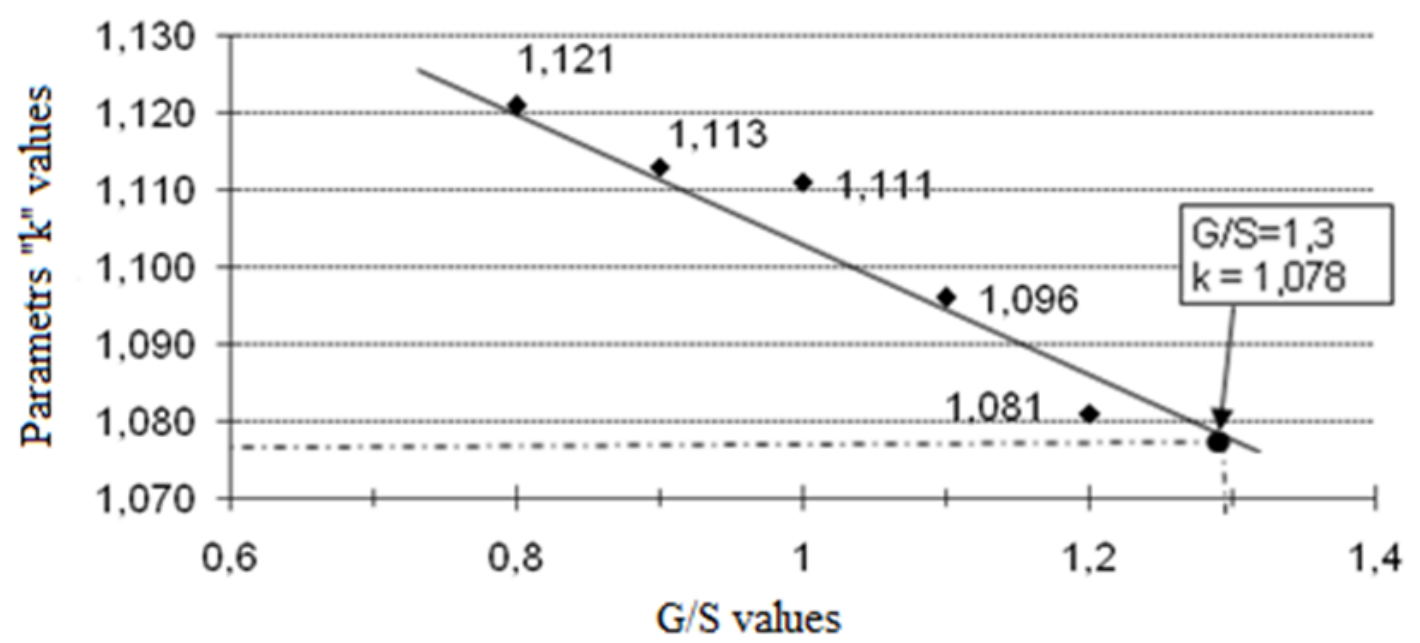

Fig 4. Variation of parameter "k" with respects to $G / S$. 
To validate this approach on a concrete made with a $G / S=1.3$, with the corresponding value of parameter $\mathrm{k}=1.078$ (Figure 4); the continuation consists to determine the volume of aggregates to associate with a volume $\left(\mathrm{V}_{\mathrm{p}}\right)$ of self-compacting cement paste.

For that purpose, we determine values of coefficients $a$ and $b$. Coefficient $a$ represents aggregates proportion having diameters greater than 80 microns in total granular volume (Eq.3). For $\mathrm{G} / \mathrm{S}=1.3$, grading analysis gave $(a=0.918)$.

$a=\frac{V_{G>80}}{V_{G}} ; b=\frac{V_{E A}}{V_{G}}$

Coefficient $b$ represents the transformed value of aggregates mass absorption, its value is $(b=$ 8.102) \%.

Considering uncertainty $( \pm 5$ liters) with which aggregates measures were made, total granular volume (sand and gravels) calculated is then:

$\mathrm{V}_{\mathrm{G}}=687 \pm 5$ liters $/ \mathrm{m}^{3}$ of concrete.

The proportion of water retained by aggregates can be determined through (Figure 5), representing a linear regression of the ratio $\left(\mathrm{V}_{\mathrm{ER}} / \mathrm{V}_{\mathrm{G}}\right)$ with respects to values of $\mathrm{G} / \mathrm{S}$.

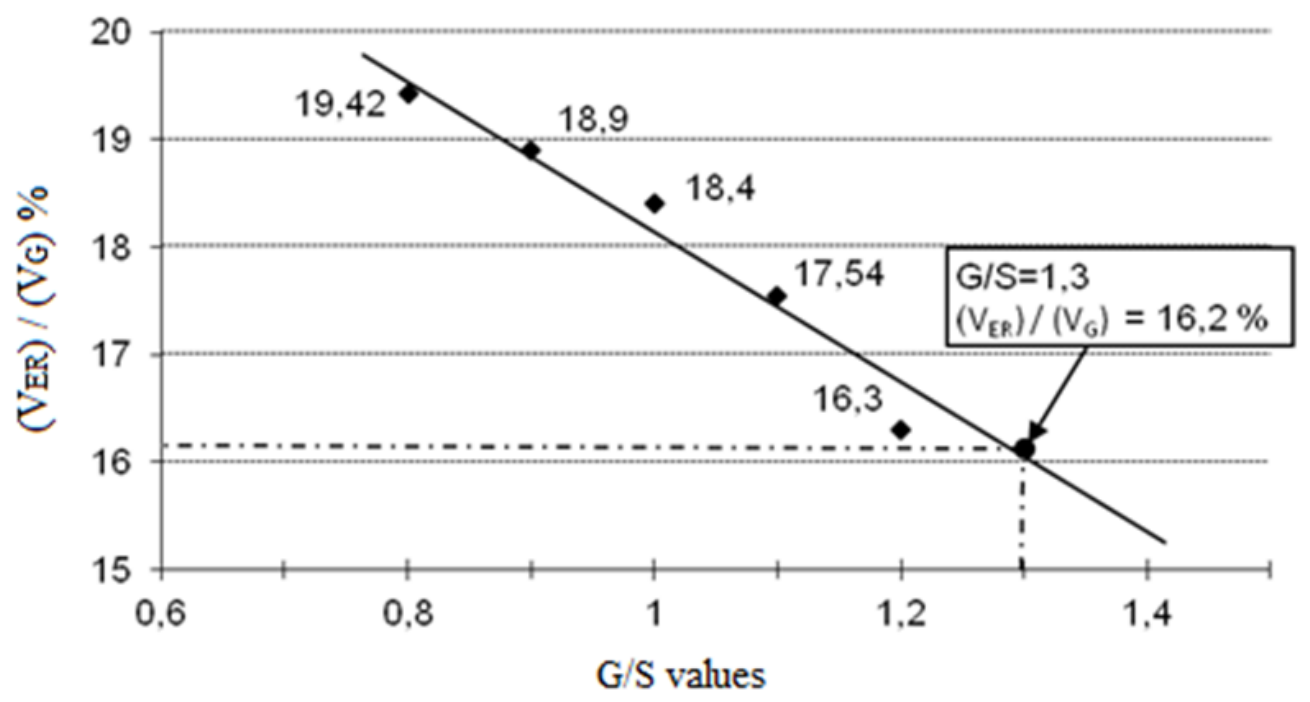

Fig 5 . Water retained by aggregates with respects to $\mathrm{G} / \mathrm{S}$.

Once the necessary elements were determined, concrete is made with the same procedure and in the same conditions as the previous concretes, and then workability characterization will be made. Table 9 shows concrete composition with $\mathrm{G} / \mathrm{S}=1.3$.

Table 9. Concrete composition with $\mathrm{G} / \mathrm{S}=1.3$.

\begin{tabular}{|c|c|c|}
\hline Component & Volume $\left(\mathrm{l} / \mathrm{m}^{3}\right.$ of concrete) & Mass $\left(\mathrm{Kg} / \mathrm{m}^{3}\right.$ of concrete) \\
\hline \hline \multirow{2}{*}{$\mathrm{G}$} & Gravel $(3 / 8): 181.4$ & 488 \\
\cline { 2 - 3 } & Gravel $(8 / 15): 184.8$ & 499 \\
\hline $\mathrm{S}$ & 296.2 & 785 \\
\hline $\mathrm{C}$ & 103.2 & 325 \\
\hline $\mathrm{F}$ & 17.2 & 48.25 \\
\hline $\mathrm{Sp}$ & 4.2 & 4.6 \\
\hline $\mathrm{W}$ & 187.9 & 187.9 \\
\hline Total & 975 & 2337.8 \\
\hline
\end{tabular}

Workability characterization tests results are shown in Table 10, according to AFGC recommendations, it shows that the concrete obtained presents self-compacting characteristics. 
Table 10. Concrete properties with $G / S=1.3$.

\begin{tabular}{|c|c|c|}
\hline \multicolumn{2}{|l|}{$\mathrm{G} / \mathrm{S}$} & 1.3 \\
\hline \multirow[t]{2}{*}{ Abrams cone } & $\mathrm{T}_{50}(\mathrm{~s})$ & 2.8 \\
\hline & Dmoy $(\mathrm{mm})$ & 696 \\
\hline \multirow[t]{2}{*}{ L Box } & $\mathrm{T} 40(\mathrm{~s})$ & 1.9 \\
\hline & $\mathrm{H}_{2} / \mathrm{H}_{1}$ & 0.95 \\
\hline \multicolumn{2}{|c|}{ Sieve stability $\pi \%$} & 12.8 \\
\hline \multicolumn{2}{|c|}{ Occluded air \% } & 3 \\
\hline \multicolumn{2}{|c|}{ Density } & 2380 \\
\hline \multicolumn{2}{|c|}{ Compressive strength Rc28 (MPa) } & 42.3 \\
\hline
\end{tabular}

The results prove that obtained concrete is self-compacting, also, visually the made concrete does not present segregation or blocking during its characterization in spreading and L-box tests respectively.

\section{Conclusions}

Excess paste theory was used in this study to determine cement paste thickness coating every aggregate of diameter given constituting the granular skeleton, and then generalized for total paste quantity determination, allowing the flow of concrete by decreasing frictions between grains of its granular skeleton. The approach was also validated experimentally. Influence of granular distribution was minimized by using an approach based on aggregates average diameter determination. This required bringing in calculations a homothety factor " $k$ ", which can be similar for concretes of different size grading but of the same aggregates type (crushed in our study).

Concrete formulations having self-compacting characteristics pass at first by determination of a sufficiency paste allowing its flow without frictions between its aggregates and to balance the mixture by a quantity of water retained by aggregates. This method based on the cement paste optimization is interesting in the sense where it is based on a mixed study: theoretical and experimental.

Self-compacting cement pastes into which it is injected wet aggregates form self-compacting concrete; which at fresh state satisfies the AFGC recommendations. In other words, it can be concluded that self-compacting characteristics of a concrete would come from the cement paste which compose it.

\section{References}

AFGC, Association Française de Génie Civil (2008). Recommendations for use of self-Compacting Concrete. Scientific and technical documents, P N B@P.

Bui VK, Akkaya Y, Shah S P (2002). Rheological model for self-consolidating concrete. ACI Mater J, 99: 54959.

El-Barrak M, Mouret M, Bascoul A (2009). Self-compacting concrete paste: Hierarchical classification of their influence on flow properties of the paste. Cement Concrete Compos 31: 12-21.

Mebrouki A, Belas N, Bouhamou N (2010). Experimental plans method to formulate a self- compacting cement paste. Mater Tehnol, 44:13-20.

Nanthagopalan P, Santhanam M (2010). A simple and systematic mix design procedure for selfcompacting concrete. $6^{\text {th }}$ International RILEM Symposium on SCC, Montreal, Canada, pp: 54-63.

Pedersen B, Smeplass S (2003). The relationship between the rheological properties of SCC and the corresponding matrix phase. Proceedings of $3^{\text {rd }}$ RILEM International Symposium on Self Compacting Concrete, Reykjavik, Iceland, pp:106-16.

Wong HHC, Kwan AKH (2008), Packing density of cementitious materials: part 1-measurement using a wet packing method. Mater Struct, 41: 689-701. 